Case Report

\title{
Cranial Impalement of a Falling Fence Spike in a Child: A Case Report
}

\author{
Jimoh Abdullahi Onimisi ${ }^{1}$, Guga Dung Apollos ${ }^{1}$, Mathew Mesi ${ }^{1}$, Danjuma Sale ${ }^{2}$ \\ ${ }^{1}$ Neurosurgery Division, Department of Surgery, Ahmadu Bello University Teaching Hospital, PMB 06, Shika-Zaria, Kaduna State, Nigeria \\ ${ }^{2}$ Department of Surgery, Barau Dikko Teaching Hospital, Kaduna, Kaduna State, Nigeria
}

Email address:

sirjimoh2002@yahoo.com (J. A. Onimisi)

\section{To cite this article:}

Jimoh Abdullahi Onimisi, Guga Dung Apollos, Mathew Mesi, Danjuma Sale. Cranial Impalement of a Falling Fence Spike in a Child: A Case Report. Journal of Surgery. Vol. 4, No. 2, 2016, pp. 31-34. doi: 10.11648/j.js.20160402.16

Received: February 11, 2016; Accepted: February 26, 2016; Published: May 6, 2016

\begin{abstract}
Cranial impalement injuries are rare. They occur from a variety of objects, and via different mechanisms. We describe the case of a 5-year old boy who suffered cranial impalement injury via a unique mechanism. He presented to our centre with an impacted $17.8 \mathrm{~cm}$ long metallic rod (a fence spike) in the vertex of his cranium, just off the midline. The spike penetrated his head and broke off its supporting frame as the frame was falling off a collapsing brick fence. He was transported as soon as possible to the hospital by relatives, without any attempt to remove the impaled spike. An urgent cranial computerized tomogram was done, and the object was removed under general anaesthesia in the operating theatre. The patient had complete recovery and was subsequently discharged from the hospital, with no residual neurological deficit. This case demonstrates a rare mechanism of cranial impalement. It also highlights the importance of following basic principles in the management of such injuries.
\end{abstract}

Keywords: Penetrating Head Injury, Foreign Object, Metallic Rod, Brick Wall, Cranio-facial

\section{Introduction}

Impalement injuries describe unusual circumstances in which a foreign object penetrates and embeds in a body part. The object often remains part of the wound and is highly conspicuous. [1] Cranial penetrating injuries caused by foreign objects other than bullets or glass from traffic crashes are quite rare, and cranial impalements are even rarer. [1-5] This is because the head presents a much smaller target compared to the rest of the body, due to its relatively smaller surface area. In addition, the face presents protective reflexes, allowing the potential victim, if unrestrained, to move away from the coming object. [1]

An extensive list of objects have been reported to cause impalement injuries in children including the rotor blade of a fan, electric plug, pencil, dart, wooden chopstick, curtain rail, defective badminton racquet, metallic cloth hanger, knife, nail, fork, scissors, and other assorted objects. [4-12] Cranial penetration is most commonly through thin bones of the skull, especially the orbital surfaces and the squamous portion of the temporal bone. [12]
Unless an associated hematoma or infarct is present, cerebral damage caused by cranial impalement is largely restricted to the wound tract. Unlike in missile injuries, there is no concentric zone of coagulative necrosis caused by dissipated energy; and unlike in motor vehicle accidents, no diffuse shearing injury to the brain occurs. [12] However, more extensive cerebral and/or vascular damage is an ever present danger if the foreign object is mobilized or removed prematurely, and this is one of the key considerations in patient handling. [13]

The management of impaled foreign objects usually presents a challenge. This relates to removal of the object, control of haemorrhage and prevention of infection in the acute phase. [14, 15] Some of the basic principles involved include: 1. stabilization/minimal manipulation of the object before and during transportation, 2. adherence to the basic principles of airway and breathing control with control of haemorrhage + adjuncts (analgesia, antibiotics, anticonvulsants), 3. clinical and radiological evaluation + pre-operative planning, 4. multidisciplinary approach (where applicable) and 5. wound care. [2, 16] 
The principle of stabilization and minimal manipulation of the object during transportation, resuscitation, investigation and movement to the theatre, is one of the cornerstones of successful management as it ensures that the tamponade-like effect on damaged vascular structures is maintained, until adequate access has been achieved intra-operatively, for controlled removal of the object and prompt haemostasis. It also limits further damage to the brain and blood vessels, thus helping ensure a good outcome. [13] Generally, less than $10 \%$ of penetrating head injuries in children result in permanent brain injury. [7] Complications such as residual neurologic deficits, CSF fistula, recurrent meningitis and cerebral abscess however, are all possible following cranial impalement injuries. $[2,8]$

\section{Case}

We present the case of a 5-year old boy, who suffered a cranio-cerebral impalement injury from a metallic fence spike, which penetrated his head and broke off its supporting frame (fig. 1) as the frame was falling off a collapsing brick fence at a neighbour's house. The boy was playing near the fence with his peers, when the incident occurred. No attempt was made at removal, and he was transported to our Accident and Emergency unit with the impacted rod insitu. He vomited recently ingested feeds twice in transit - non bilious, nonprojectile. He also complained of pain at the site, but had no convulsion, loss of consciousness or visual impairment.

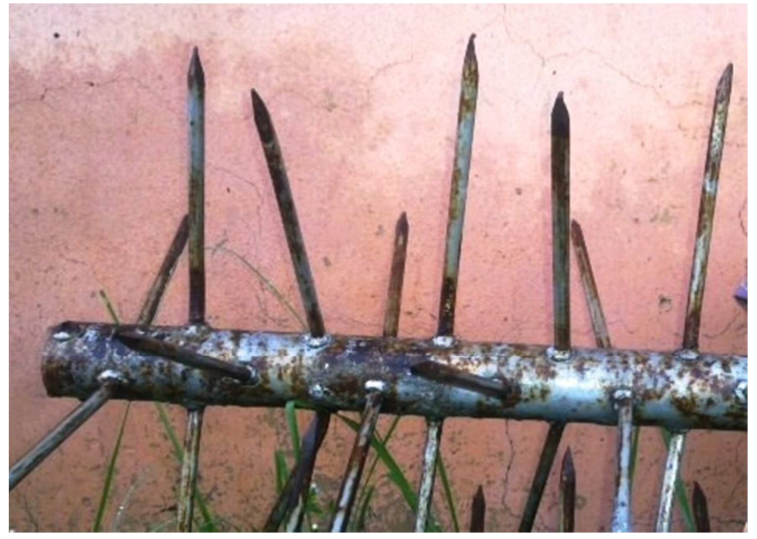

Fig. 1. Fence spikes on metallic frame.

He had a stable cardio-respiratory status on presentation. A metallic rod, $9 \mathrm{~mm}$ in diameter, was embedded in the vertex of his cranium, about $1 \mathrm{~cm}$ to the right of the midline, and about $10 \mathrm{~cm}$ superior to the external occipital protuberance. Approximately $10 \mathrm{~cm}$ of the spike was projecting out of the cranium, with surrounding scalp oedema, but no obvious bleeding was noted (fig. 2). Neurological examination revealed a Glasgow coma scale score (GCS) of 14, anisocoria and right hemiparesis. An urgent cranial computerized tomogram revealed a $7.5 \mathrm{~cm}$ intracranial extension of the spike (fig. 3), with the pointed tip located just lateral to the left ventricle (fig. 4). No intracranial haemorrhage was seen.

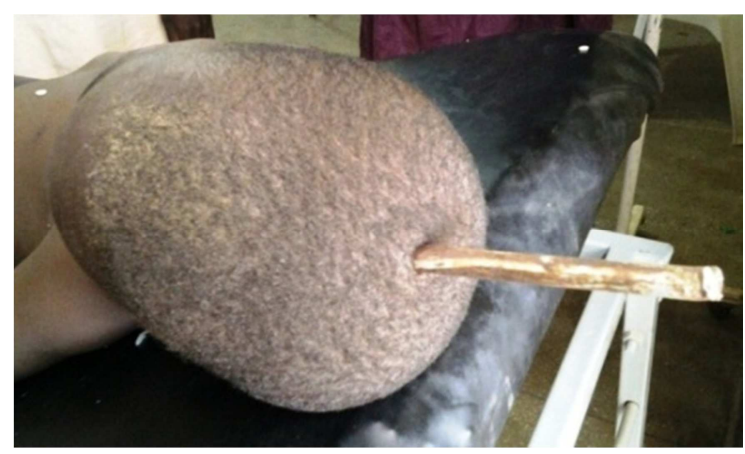

Fig. 2. Impaled fence spike.

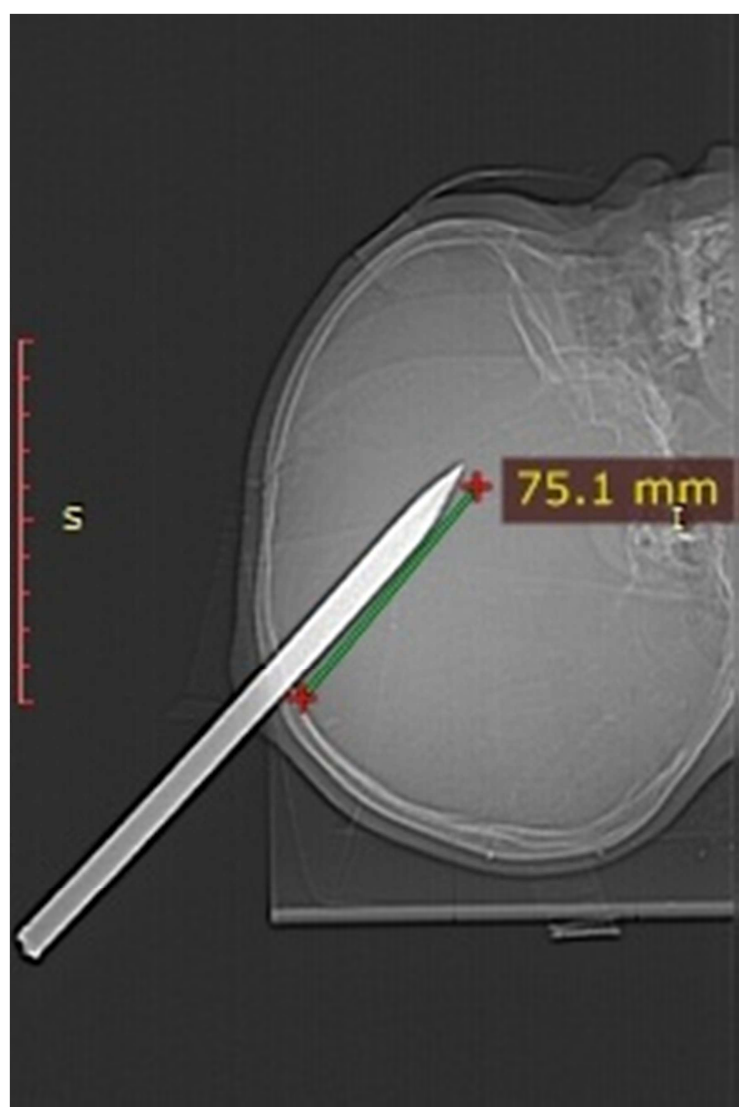

Fig. 3. CT scanogram-impaled spike insitu.

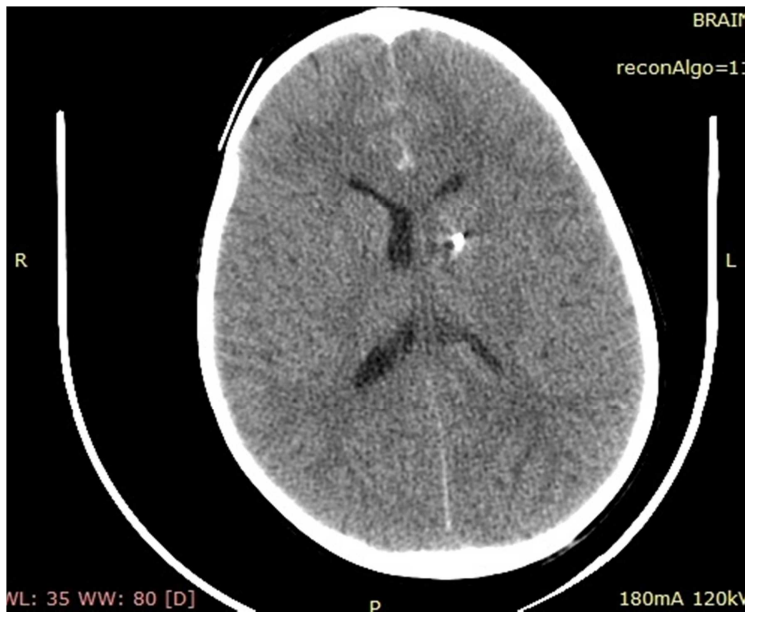

Fig. 4. Cranial CT scan-note tip of spike lateral to the left ventricle. 
The patient was resuscitated. Analgesics, broad spectrum intravenous antibiotics antiseizure and tetanus prophylaxes were commenced.

Under general anaesthesia in the operating theatre, via an S-shaped scalp incision across the point of entry, sagittal scalp flaps were raised, exposing the underlying elevated skull fracture (fig. 5), and freeing the rod which was then gently removed with minimal resistance. Brisk venous bleeding was encountered and was controlled with oxidized cellulose. The tract was irrigated with saline and cleaned with povidone iodine. The scalp wound was closed and a sterile dressing applied.

He had a good post-operative recovery. Antibiotics were given for a total of 4 weeks. He was discharged from the hospital on the $18^{\text {th }}$ post-operative day, with no residual neurological deficit and no new complaints at discharge and on subsequent follow-up visits up to one year post-surgery.

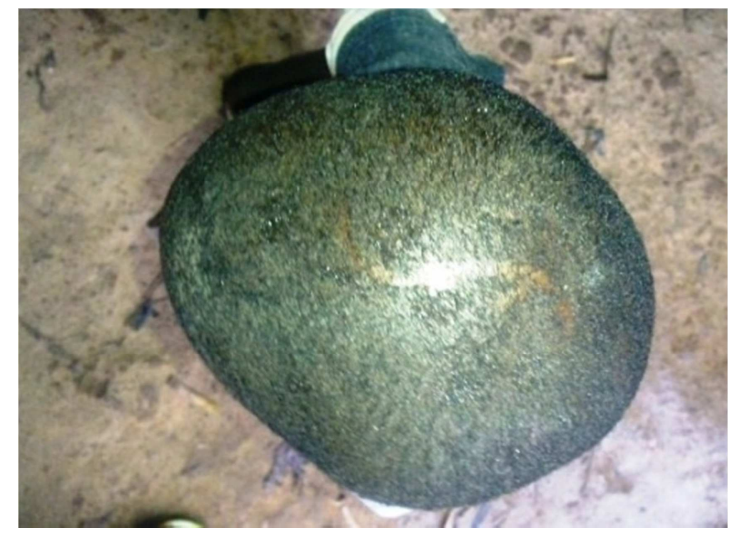

Fig. 5. Post-op - note scar on cranial vault.

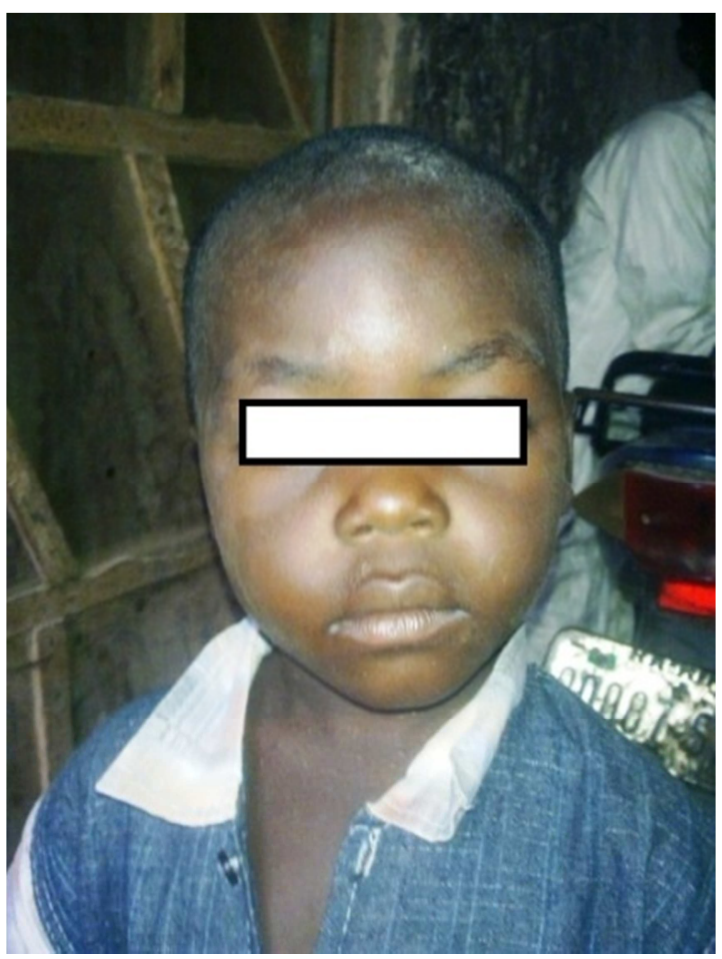

Fig. 6. Post-op

\section{Discussion}

This case represents a unique injury pattern, with an unusual mechanism. Reports have been made of impalement injuries suffered due to falls from heights unto fence or construction rods. $[12,17]$ To our knowledge, this is the first report of cranial impalement from a falling fence spike which penetrated the victim's head and broke off its supporting frame, all from a collapsing fence. Another unique feature of this injury is the point of penetration and trajectory of entry - just to the right of the midline extracranially, but crossing the midline intracranially, into the left cerebral hemisphere. The middle third of the superior sagittal venous sinus, was injured as evidenced by the brisk venous bleeding encountered intra-operatively. This was however, a small laceration, which was easily controlled with a local haemostatic agent.

The principle of not manipulating the foreign object was observed by the relatives during prompt transportation to the hospital. This was despite the fact that they had no prior training either in emergency service delivery, or in the management of impalement injury. This principle was also observed during resuscitation at our Accident and Emergency unit. Some authors have reported removal of an impaled metal rod in the Emergency Room, before subsequent debridement and cranio-facial reconstruction in the operating theatre. Their decision was based on the conclusion that the trajectory of the rod did not put any major vessel at risk of injury. [12] They however also acknowledged that it was a hasty undertaking, and could have resulted in more devastating neurological sequelae. We did not attempt this on our patient, based on principle, and also on the knowledge that the superior sagittal sinus was likely lacerated, albeit small. Any attempt to pull out the object at the scene of the injury, or even at our Accident and Emergency unit, outside the controlled theatre environment; might have resulted in further damage to the superior sagittal venous sinus and brain parenchyma with possible devastating consequences.

Various forms of intracranial infection such as meningitis, epidural abscess, subdural empyema and cerebral abscess have been documented following cranial impalement injuries. [12] Adequate measures against such were instituted in the management of this patient. These measures included early institution of antibiotic therapy, prophylaxis against tetanus infection and irrigation of the tract following removal of the impaled object.

This patient had complete recovery with no residual neurological deficit at discharge and on subsequent follow-up. This is a result of observing the basic principles of managing impalement injuries. It may also relate to the fact that cerebral damage in cranial impalement is largely restricted to the wound tract, and hence often not extensive. [12]

\section{Conclusion}

This case depicts a unique mechanism of cranial impalement. It demonstrates the importance of following basic principles in the management of such injuries. It also 
typifies the good outcome achievable in most patients, when properly managed, despite the very gross nature of this type of injury.

\section{References}

[1] B. L. Eppley, Craniofacial impalement injury: a rake in the face., vol. 13. 2002, pp. 35-37.

[2] S. W. Kim, S. K. Youn, J. T. Kim, S. H. Cho, Y. H. Kim, and K. T. Hwang, "Management of an Unusual Craniofacial Impalement Injury by a Metallic Foreign Body," Journal of Craniofacial Surgery, vol. 23. pp. e140-e146, 2012.

[3] J. Koestler and R. Keshavarz, "Penetrating head injury in children: a case report and review of the literature," The Journal of Emergency Medicine, vol. 21. pp. 145-150, 2001.

[4] A. Kumar, H. Singh, and K. C. Sharma, "Penetrating head injury from a pedestal fan rotor blade in a child - An unusual case," Pediatr. Neurosurg., vol. 42, pp. 391-394, 2006.

[5] A. López González, A. Gutiérrez Marín, J. A. Álvarez Garijo, and M. Vila Mengual, "Penetrating head injury in a paediatric patient caused by an electrical plug," Child's Nerv. Syst., vol. 22, pp. 197-200, 2006.

[6] S. K. Aremu, M. M. Makusid, and I. C. Ibe, "Oro-cranial penetrating pencil injury," Ann. Saudi Med., vol. 32, pp. 534 $536,2012$.

[7] W. W. Chan and K. A. Choudhari, "Penetrating head injury caused by a dart," Ir. Med. J., vol. 101, 2008.

[8] S. KAWAMURA, H. HADEISHI, N. SASAGUCHI, A. SUZUKI, and N. YASUI, "Penetrating Head Injury Caused by Chopstick - Case Report—," Neurologia medico-chirurgica, vol. 37. pp. 332-335, 1997.
[9] A. Lauterbach, R. Hausmann, and P. Betz, "Fatal impalement injury of the head due to a curtain rail," Int. J. Legal Med., vol. 120 , pp. 380-382, 2006.

[10] D. Pappano, E. Murray, L. B. Cimpello, and G. Conners, "Penetrating missile-type head injury from a defective badminton racquet," Eur. J. Pediatr., vol. 168, pp. 749-751, 2009.

[11] A. Walls, M. Pierce, H. Wang, and E. H. Harley, "Clothing hanger injuries: pediatric head and neck traumas in the United States, 2002-2012.," Otolaryngol. Head. Neck Surg., vol. 150, pp. 300-4, 2014.

[12] M. Miscusi, P. Arangio, L. De Martino, F. De-Giorgio, P. Cascone, and A. Raco, "An unusual case of orbito-frontal rod fence stab injury with a good outcome.," BMC Surg., vol. 13, no. 1, p. 31, Jan. 2013.

[13] H. Inoue, N. Hitosugi, T. Cho, K. Kamishima, T. Kanayama, K. Ogawa, T. Arai, Y. Kuno, M. Tsuchida, and Y. Okuda, "A case of craniofacial injury by javelin," Japanese J. Anesthesiol., vol. 55, pp. 1416-1419, 2006.

[14] N. C. H. Keong, J. R. W. Gleave, and P. J. Hutchinson, Neurosurgical history: Comparing the management of penetrating head injury in 1969 with 2005., vol. 20. 2006, pp. 227-232.

[15] L. M. Jacobs, L. D. Berrizbeitia, and J. Ordia, Crowbar impalement of the brain., vol. 25. 1985, pp. 359-361.

[16] I. P. Kelly, S. E. Attwood, W. Quilan, and M. J. Fox, The management of impalement injury., vol. 26. 1995, pp. 191-193.

[17] J. Missliwetz, Fatal impalement injuries after falls at construction sites., vol. 16. 1995, pp. 81-83. 